\title{
Finding, Saving, and Relocating \\ Dick, Jane, Alice, Jerry, Janet and John: Historical and Archival Collections in Education
}

\author{
By Nancy P. O'Brien \\ University of Illinois at Urbana-Champaign
}

\begin{abstract}
In summer, 2002, the Education Division of the Special Libraries Association held a panel presentation on "Historical and Archival Collections in Education." From that session developed this article which discusses the need for finding aids, publicity, creative uses of the web, and collaborative ways to deal with these issues. Specific references to finding aids and web sites of interest to education historians and librarians, and brief descriptions of several special collections of historical education materials are included. Also highlighted is a new service, an exchange registry, which offers institutions a way to place materials where they are most needed.
\end{abstract}

The lack of visibility for collections of historical education materials is one of the most disheartening aspects for those that work with and try to develop and promote these collections. Many others have addressed the need for these collections and the uses made of them. This paper discusses the need for finding aids, publicity, creative uses of the web, and collaborative ways to effect change.

There are outstanding collections of research materials related to the history of American education scattered across the United States. Gutman Library at Harvard University houses some unique reports from schools and academies from the eighteenth and nineteenth centuries, for example. Teachers College at Columbia University has unique textbook materials from other countries, as well as an excellent collection of American textbooks. The University of Pittsburgh houses an exceptional collection of textbooks, with a strong emphasis on historical school books used in the Pennsylvania region. However, there are smaller places than the more obvious research libraries collecting historical schoolbooks and other related materials. For example, Miami University of Ohio houses a collection of McGuffey readers since McGuffey was affiliated with that institution. The University of South Carolina houses a number of specialized materials, particularly those that relate to the Progressive era in education. And, even in the larger research institutions, surprising and specialized collections may be found. For example, at the University of Illinois, there is a collection of twenty-three primers from Argentina published during the Peron period. Entitled PeronEvita, these unique resources reflect the Peronist period, often include references to Evita as the spiritual leader of Argentina, and contain the signature of Juan Peron in one of the schoolbooks (Albornoz de Videla, 1953). What researcher would think to look for Evita on the prairie?

\section{Existing Sources}

With all of these examples, it becomes clear that better finding aids to the wealth of materials tucked away in special collections, research libraries, and archives need to be made available. While some resources exist, these are rather dated and not as comprehensive as is desirable. Three sources immediately come to mind to assist researchers and librarians: the 1988 Directory of Historical Curriculum Collections, published by an Ad hoc Subcommittee of the Education and Behavioral Sciences Section, Association of College and Libraries, American Library Association; the 1995 International Guide for Research in the History of Education, published for the International Standing Conference for the History of Education; and the History of Education Museums and Collections International Directory, published by the Blackwell History of Education Research Collection at Northern Illinois University in 1993/1994. Clearly these print resources are all rather dated. However, efforts are underway to update at least two of these sources, and there is surprisingly limited overlap among these three items. The International Guide for Research in the History of Education is now available as a searchable web database, according to the organization's web site. The web version is comparable to the print version of the second edition that offers access to a number of specialized collections of education 
resources, particularly in the European area. The rather outdated Directory of Historical Curriculum Collections is in the process of being updated by another Ad hoc committee within the Education and Behavioral Sciences Section of the Association of College and Research Libraries. The new guide will focus on collections of historical textbook and curriculum collections in the United States and Canada, however, rather than on specialized collections of school reports, college catalogs, or other materials that may also be useful to education historians. Another option to improve access to such specialized materials might be to participate in the International Guide's searchable database by submitting information for U.S. institutions which is sadly lacking, as is coverage of the African nations. Encouraging researchers to identify sites for this database would be a valuable collaborative effort.

The History of Education Museums and Collections International Directory has been erratic in its publication, and is unlikely to be updated at any time soon, according to the publisher. However, the most recent edition does contain some unique features, such as a list of American country schools, taken from Andrew Gulliford's America's Country Schools, now in its third edition (1996). The advantages of having this type of information included in a directory are numerous for the researcher. The History of Education Museums and Collections guide is international in scope, but like others, the coverage is primarily European with three Latin American countries and Australia thrown in for balance. The bulk of this directory covers the United States, of course, and provides information about museums and special collections that contain materials of interest to education historians. The list of American country schools and one room schoolhouses adds value to this resource.

\section{World Wide Web Access}

One of the most exciting recent developments in being able to locate historical materials is access provided through the World Wide Web. Such web sites often need better organization, though, since they tend to jumble categories of materials together and require constant linking to sites to determine whether an item is a primary source or a list of other resources. That lack of organizational focus is why efforts to update existing directories are still valid.
The web offers a variety of options that did not previously exist for promoting or listing resources for an international audience of researchers. For example, actual full-text images from nineteenth century schoolbooks have been digitized and made available on the web by the University of Pittsburgh's Library system. One hundred forty textbooks have been digitized, as well as John Nietz's 1961 and 1966 surveys of American schoolbooks (http://digital.library.pitt.edu/nietz/). This rich resource for historians provides access to materials without the necessity of travel. Even so, there are advantages to having access to the actual artifact. For example, a health and hygiene schoolbook (Smith, 1884) found in the digitized collection, while faithfully scanned in, does not contain the homely touches that the artifact may have. Pittsburgh's digitized version of Smith's book does not include images of the book cover. The Library at the University of Illinois at UrbanaChampaign holds not only the 1884 book, but the author's primer on the same topic (Smith, 1885). The University of Illinois copy of the primer has been carefully covered in a hand-stitched fabric cover, presumably to hide the title as the student walked back and forth from school at the end of the nineteenth century. With contents that address issues such as smoking, alcohol, and other "unclean" habits, a nineteenth century student might justifiably hide the title of this provocative primer. Despite the wonders of the web, these touches may be lost unless researchers demand consistency in the preservation and digitization of such items.

Many of the larger research collections, such as Harvard University and Teachers College at Columbia University provide information on the web about their historical collections. At the Harvard site, one can find information about the historical textbook collection as well as public school reports, private school catalogs, and teacher training programs, with images from the collection to tantalize the researcher (http://www.gse.harvard. edu/library/collections/sc_textbooks). Teachers College offers a text summary of their extensive special collections in the history of education that contain materials dating from the fifteenth century, American textbooks published before 1900, and international education textbooks (http://www.tc. columbia.edu/a\&h/history-ed/hb-collections.htm).

Other locations of textbooks are not as easily searchable on the web. For example, the Center for Research Libraries in Chicago houses 72,000 schoolbooks from the eighteenth through the 
twentieth centuries, but none of these is cataloged or accessible by searchable databases at this time. Fully half of the 56,000 textbooks in University of Illinois Library collection are uncataloged due to resource shortages. However, like most research institutions, the cataloged segment of the collection is searchable through the online catalog to anyone worldwide (http://wwwcrl. uchicago.edu/content/textbooks). Borrowing of materials through interlibrary loan is often possible for these items.

Researchers seeking information may find their efforts facilitated by web sites of specific interest to education historians. For example, the Textbook Colloquium in the United Kingdom has not only a web page with papers from relevant conferences on it (http://www.open.ac.uk/OU/Aca demic/Arts/TEXTCOLL), but also a print publication, Paradigm, that addresses history of education topics. Back issues of Paradigm are also available on the web, and include articles and essays that are international in scope (http://faculty.ed.uiuc.edu/westbury/paradigm/).

Many other professional associations also have web sites, some containing content and links to research materials. With all of these wonderful resources available, many of them listed on the web, questions still arise regarding location, accessibility and content of these collections. Those questions can be answered by the forthcoming directories, or by other collaborative efforts.

One collaborative effort that drew together education stakeholders was the National Education Network (NEN). This outreach organization was affiliated with the National Library of Education and had as its mission to "to preserve the education past, connect the education present, and shape the education future by providing and supporting comprehensive access to education information." While this organization is currently transitioning to one that is less dependent on the $\mathrm{Na}$ tional Library of Education, it still has web sites sponsored at Harvard and Syracuse universities that provide useful information to current practitioners as well as education historians. One of the services offered through this web site is an Education Materials Exchange Registry. Basically, this is an eBay ${ }^{\circledR}$ type of web site, allowing institutions to list materials that they would like to offer to other institutions, or that they would like to add to their collections. For those people familiar with similar library listings, this is a "needs and offers" list. The purpose of this registry is to allow for the placement and preservation of education materi- als rather than having them sent to the nearest landfill. Promotion of this web site to education librarians, archivists, historians and others will help preserve education materials so that they are not lost as have been so many other historical items.

\section{Publicizing Sources}

One way to publicize special collections of education materials is for institutions to provide easily searchable descriptions on the web, using terms likely to be picked up by various search engines. Another publicity mechanism is developing exhibits and distributing information about them. Accompanying these exhibits with a graphically appealing web site offers further access to the collections as well as publicity. Another way to promote collections is to host speakers at institutions with significant collections or develop workshops or conferences related to these resources. Nostalgia for childhood readers may draw some of the audience but the wealth of resources will be sure to impress them and linger in their memories. Knowing about these special collections will encourage audience members to discuss them and share that knowledge with others.

While the amount of work involved in identifying education history collections, promoting their availability, and preserving the content may seem overwhelming, these are important activities. Unless a beginning is made now, more and more of these materials will be lost to deterioration, disposal due to lack of space, or simple lack of knowledge about which institutions would be happy to accept a donation of these types of materials. Most of the major research institutions will gladly accept donations of older education materials that are unique and do not duplicate their existing holdings. The NEN exchange registry will help to identify good homes for needy books and reports. As our most popular characters from school readers would testify, there is an invaluable social and historical content stored in the pages of schoolbooks and other education resources. So, in the words of Dick and Jane (New Basic Readers), Alice and Jerry (The Alice and Jerry basic reading program), and Janet and John (the British version of Alice and Jerry repackaged for distribution to the Empire), "Find books! See books to save! Save books, please!" 


\section{Notes}

Miami University of Ohio has a brief description of the William Holmes McGuffey schoolbooks collection of 336 items and a searchable database at: http://www.lib.muohio.edu/libinfo/depts/spec/ (Accessed March 31, 2005); information about the McGuffey papers and museum may be found at: http://www.lib.muohio.edu/mcguffey/.

The Museum of Education, University of South Carolina, Columbia, includes information about educational life in South Carolina as well as national trends in curriculum, primarily in a Progressive tradition, at the Museum and its Web site: http://www.ed.sc.edu/MusofEd/index.htm.

Dick and Jane are characters from The New basic readers by William S. Gray and others. The 1954 edition was published in Chicago by Scott, Foresman and Co. Many other editions were published. Alice and Jerry were featured in The Alice and Jerry books by Mabel O'Donnell. Beginning in the 1930s, many editions were published in Evanston, Illinois by Row, Peterson, and Company, and their various successors. Janet and John were actually the Anglicized version of Alice and Jerry. Originally published by Row Peterson and Company for author Mabel O'Donnell; the British publisher, James Nisbet and Company, repackaged the series and published it in London as the Janet and John books.

\section{References}

Albornoz de Videla, G. (1953). Evita: Libro de Lectura Para Primer Grado Inferior. Buenos Aires: Edit. L. Lasserre.

Caspard, P. (1995). International Guide for Research in the History of Education. ( $2^{\text {nd }}$ ed.) Paris : Institut National de Recherche Pedagogique; Bern: P. Lang. A database of updated information available at the Web site of the institution: http://bdd.inrp.fr:8080/mgi/gb_ MultiWelcome.html.

History of Education Museums and Collections International Directory (1993/1994). Dekalb, IL: Blackwell History of Education Research Collection, Northern Illinois University. Information about the publisher may be found at: http://www.cedu.niu.edu/blackwell/.

Directory of Historical Curriculum Collections. (1988). Compiled by the Ad hoc Subcommittee on Historical Curriculum Collections, Education and Behavioral Sciences Section, As- sociation of College and Research Libraries, American Library Association. Chicago: The Association. Also available as ERIC Document No. ED313045.

Gulliford, A. (1996) America's Country Schools. (3rd ed.) Niwot, CO: University Press of Colorado.

Nietz, J. (1961). Old Textbooks: Spelling, Grammar, Reading, Arithmetic, Geography, American History, Civil Government, Physiology, Penmanship, Art, Music, as Taught in the Common Schools from Colonial Days to 1900. Pittsburgh: University of Pittsburgh Press.

Nietz, J. (1966). The Evolution of American Secondary School Textbooks; Rhetoric \& Literature, Algebra, Geometry, Natural History (Zoology), Botany, Natural Philosophy (Physics), Chemistry, Latin And Greek, French, German \& World History as Taught in American Latin Grammar School Academies and Early High Schools before 1900. Rutland, VT: C. E. Tuttle.

Smith, W.T. (1884). The Human Body and Its Health; A Text-Book for Schools, Having Special Reference to the Effects of Stimulants and Narcotics on the Human System. New York: Ivison, Blakeman, Taylor \& Co.

Smith, W.T. (1885). Primer of Physiology and Hygiene: A Text-Book For Primary Classes: With Special Reference to the Effects of Stimulants and Narcotics on the Human System. New York: American Book Co.

Nancy P. O'Brien is Head, Education \& Social Science Library, University of Illinois at UrbanaChampaign, E-mail: npobrien@uiuc.edu

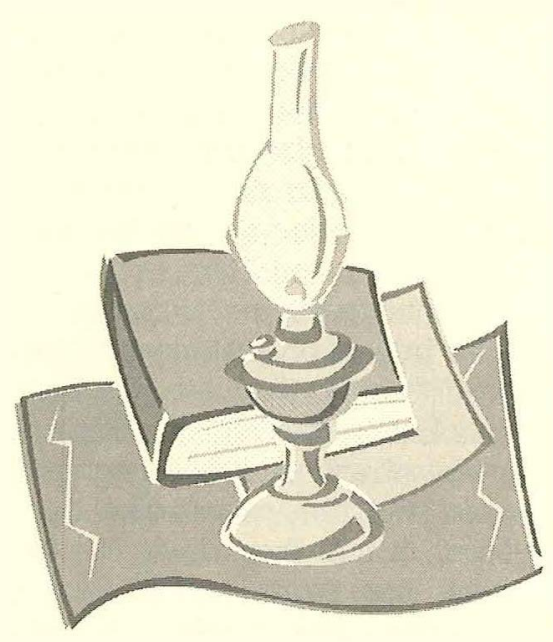

